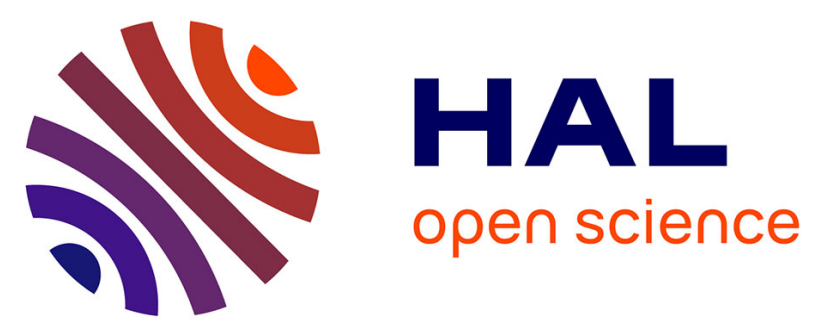

\title{
Effect of composition and high-temperature annealing on the local deformation behavior of silicon oxycarbides
}

C. Stabler, Fabrice Célarié, Tanguy Rouxel, R. Limbach, L. Wondraczek, R. Riedel, E. Ionescu

\section{- To cite this version:}

C. Stabler, Fabrice Célarié, Tanguy Rouxel, R. Limbach, L. Wondraczek, et al.. Effect of composition and high-temperature annealing on the local deformation behavior of silicon oxycarbides. Journal of the European Ceramic Society, 2019, 39 (7), pp.2287-2296. 10.1016/j.jeurceramsoc.2019.02.024 . hal-02050889

HAL Id: hal-02050889

https://hal-univ-rennes1.archives-ouvertes.fr/hal-02050889

Submitted on 13 Mar 2019

HAL is a multi-disciplinary open access archive for the deposit and dissemination of scientific research documents, whether they are published or not. The documents may come from teaching and research institutions in France or abroad, or from public or private research centers.
L'archive ouverte pluridisciplinaire HAL, est destinée au dépôt et à la diffusion de documents scientifiques de niveau recherche, publiés ou non, émanant des établissements d'enseignement et de recherche français ou étrangers, des laboratoires publics ou privés. 


\title{
Effect of composition and high-temperature annealing on the local deformation behavior of silicon oxycarbides
}

Christina Stabler, ${ }^{1}$ Fabrice Celarie, ${ }^{2}$ Tanguy Rouxel, ${ }^{2}$ René Limbach, ${ }^{3}$ Lothar Wondraczek, ${ }^{3}$ Ralf Riedel, ${ }^{1}$ Emanuel lonescu ${ }^{1 *}$

\author{
${ }^{1}$ Technische Universität Darmstadt, Institute of Materials Science, Otto-Berndt-Str. 3, D- \\ 64287 Darmstadt, Germany, ionescu@materials.tu-darmstadt.de \\ ${ }^{2}$ University of Rennes 1, Campus Beaulieu, Physics Institute, IPR UMR UR1-CNRS 6251, \\ Glass and Mechanics Department, 35042 Rennes cedex, France \\ ${ }^{3}$ University of Jena, Otto Schott Institute of Materials Research, Fraunhoferstr. 6, D-07743 \\ Jena, Germany
}

\begin{abstract}
:
Silicon oxycarbides with varying compositions were investigated concerning their elastic and plastic properties. Additionally, the impact of thermal annealing on their elastic properties was assessed. Phase separation of SiOC seems to have no significant impact on Young's modulus (high values of $\beta$-SiC compensate the low values of the vitreous silica matrix) and hardness. However, it leads to an increase in Poisson's ratio, indicating an increase in the atomic packing density. The phase composition of SiOC significantly influences Young's modulus, hardness, brittleness and strain-rate sensitivity: the amount of both $\beta-\mathrm{SiC}$ and segregated carbon governs Young's modulus and hardness, whereas the fraction of free carbon determines brittleness and strain-rate sensitivity. Thermal annealing of SiOC glassceramics leads to an increase in Young's modulus. However, the temperature sensitivity of Young's modulus and Poisson's ratio is not affected, indicating the glassy matrix being stable during thermal annealing. A slightly improved ordering of the segregated carbon and the $\beta$ $\mathrm{SiC}$ nanoparticles upon thermal annealing was observed. It is suggested that this is responsible for the increase in Young's modulus.
\end{abstract}

Keywords: Silicon oxycarbide, elastic properties, Poisson's ratio, plastic deformation, thermal annealing

\section{Introduction}

Amorphous silicon oxycarbides ( $\mathrm{SiOC}$ ) can basically be regarded as $\mathrm{SiO}_{2}$ glasses which are mechanically strengthened by the presence of tetrahedrally coordinated carbon atoms. Their synthesis relies on the thermal conversion of polyorganosiloxanes or precursors derived from sol-gel synthesis of organically modified alkoxysilanes [1, 2]. Via this procedure, SiOC glasses with varying chemical compositions are obtainable. Depending on the carbon content, a distinction is usually made between two groups of amorphous SiOC materials, i.e., 
glasses with low amounts of segregated carbon and carbon-rich compositions (i.e. > 20 wt.\% segregated carbon [1, 3, 4]). The chemical composition of SiOC glasses determines their structural and functional properties. Due to the remarkable high temperature stability, with a notable resistance against crystallization up to about $1500^{\circ} \mathrm{C}$ [1], SiOC glasses have attracted a growing attention for applications in combustion engines or as coatings on turbine blades. In these, knowledge on the elastic properties and plasticity of SiOC glasses, like their Young's modulus, brittleness, hardness or creep behavior, is inevitable. In particular, this includes information on the mechanical performance under extreme conditions of high temperatures and extended exposure times.

$\mathrm{SiOC}$ glasses are $\mathrm{X}$-ray amorphous and built-up of corner-sharing $\mathrm{SiO}_{4-\mathrm{x}} \mathrm{C}_{\mathrm{x}}$ tetrahedral units $\left(\mathrm{SiO}_{4}, \mathrm{SiO}_{3} \mathrm{C}, \mathrm{SiO}_{2} \mathrm{C}_{2}, \mathrm{SiOC}_{3}\right.$ and $\left.\mathrm{SiC}_{4}\right)[5,6]$. The abundance of each tetrahedral unit depends on the chemical composition and thus, the polymeric precursor used for the glass preparation. In addition to the covalently bonded C linked to Si (network carbon), typical SiOC glasses also contain a $\mathrm{sp}^{2}$-hybridized segregated carbon phase, which is homogeneously dispersed in the SiOC glass matrix [7, 8]. At temperatures above $1250{ }^{\circ} \mathrm{C}$, phase separation of the amorphous SiOC glass starts, as evident from the vanishing signals for $\mathrm{SiO}_{3} \mathrm{C}, \mathrm{SiO}_{2} \mathrm{C}_{2}$ and $\mathrm{SiOC}_{3}$ tetrahedral units in the ${ }^{29} \mathrm{Si} \mathrm{MAS} \mathrm{NMR} \mathrm{spectra} \mathrm{[7,} \mathrm{9].} \mathrm{This}$ phase separation results in the formation of $\mathrm{SiOC}$ glass-ceramics within the system $\mathrm{SiO}_{2}$ $\mathrm{SiC}-\mathrm{C}$, where the residual glass matrix is composed of $\mathrm{SiO}_{2}$ with homogeneously dispersed $\beta$-SiC nanoparticles and segregated carbon. Controlling the polymeric precursor along with the synthesis conditions enables the preparation of SiOC materials with a tailored microstructure.

The partial substitution of two-fold coordinated $\mathrm{O}$ atoms by four-fold coordinated $\mathrm{C}$ atoms in $\mathrm{SiOC}$ glasses is known to improve the glass network connectivity and, by extension, to enhance the thermal and mechanical stability. In comparison to vitreous silica, SiOC glasses typically exhibit higher Young's modulus, hardness and glass transition temperature [10-14]. Similar trends have previously been reported also for SiOC glass-ceramics [15-18]. Although the creep rates and viscosity of SiOC glass-ceramics have been found as being determined by both the chemical composition and phase composition [17, 19], information on the influence of the chemical composition and phase composition on the elastic properties of SiOC glass-ceramics remains limited. Moreover, only little is known about the impact of annealing on the elastic properties of SiOC glasses and glass-ceramics. Rouxel et al. [11] studied the Young's modulus of a SiOC glass during a thermal treatment at temperatures up to $1400^{\circ} \mathrm{C}$. Upon the phase separation above $1250^{\circ} \mathrm{C}$, an irreversible increase of Young's modulus was observed, which has been attributed to the precipitation of $\beta$-SiC nanoparticles. Beside the technological significance of these findings, there is a fundamental interest on the underlying structural changes inside the glass network. Since the Young's modulus is intimately related to the atomic structure of glasses, i.e., strength and density of the interatomic bonds [20], it can serve as an indicator for structural modifications inside the glass network during annealing or even high-temperature creep experiments [11].

Here, we report on the elastic properties and plasticity of a SiOC glass as well as a series of SiOC glass-ceramics with varying chemical and phase compositions. For selected SiOC 
glass-ceramics, the elastic properties were also monitored up to temperatures of around $1000{ }^{\circ} \mathrm{C}$. This has also been done for SiOC glass-ceramics, which have been subjected to a prior thermal treatment comparable to previous high temperature creep experiments performed on these SiOC glass-ceramics $[18,19]$.

\section{Experimental Procedure}

Materials synthesis and processing. The synthesis procedure of the investigated SiOC glass and glass-ceramics is described in detail in Refs. [18] and [21]. Different polymeric precursors were used to realize a series of SiOC materials with various amounts of segregated carbon. This includes one sample with no segregated carbon phase (denoted as $\mathrm{SiC} / \mathrm{SiO}_{2}$ ), and further samples which contain approximately 1, 12 and 16 vol.\% of segregated carbon, respectively (denoted as C1-SiOC, C12-SiOC, and C16-SiOC).

$\mathrm{SiC} / \mathrm{SiO}_{2}$ glass powder was prepared by pyrolysis of polysilsesquioxane in hydrogen atmosphere [22]. C1-SiOC was prepared by a sol-gel synthesis of triethoxysilane and methyldiethoxysilane in a 2:1 molar ratio, followed by ageing and pyrolysis [9]. C12-SiOC was synthesized via cross-linking and pyrolysis of a commercially available polysilsesquioxane (Belsil PMS MK, Wacker GmbH, Burghausen, Germany). C16-SiOC was prepared by a catalyzed sol-gel synthesis of a mixture consisting of $80 \mathrm{wt} . \%$ polymethylhydrosiloxane (PMHS; average $M_{n}$ 1700-3200; Merck, Germany) and 20 wt.\% 1,3,5,7-tetramethyl-1,3,5,7-tetravinylcyclotetrasiloxane $\left(\mathrm{D}_{4} \mathrm{Vi} ; 97 \%, \mathrm{ABCr}\right.$, Karlsruhe, Germany), followed by ageing and pyrolysis [23]. The synthesized powders were ground and sieved (particle diameter $<40 \mu \mathrm{m}$ ) and were subsequently densified for $30 \mathrm{~min}$ at a temperature of $1600^{\circ} \mathrm{C}$ and a pressure of $50 \mathrm{MPa}$ using a uniaxial hot press operating in a static argon atmosphere (these samples were used for nanoindentation). Alternatively, the densification was achieved using a Field Assisted Sintering Technique (FAST). Here, the powders were treated at the same temperature and pressure but for only $15 \mathrm{~min}$ in argon atmosphere. The samples prepared by the latter routine were used in the Resonant Frequency Damping Analyzer (RFDA). The final monolithic samples are further denoted as $\mathrm{SiC} / \mathrm{SiO}_{2}-1600, \mathrm{C1}-\mathrm{SiOC}-1600, \mathrm{C12}-\mathrm{SiOC}-1600$ and C16-SiOC-1600, respectively.

Additionally, one monolithic SiOC glass (denoted as C1-SiOC-1100) was prepared from a sol-gel derived precursor of triethoxysilane and methyldiethoxysilane in a 2:1 molar ratio. The precursor was cast in plastic boxes, followed by curing and drying. The resulting monolithic xerogels were pyrolyzed in an alumina tube furnace for $3 \mathrm{~h}$ at $1100^{\circ} \mathrm{C}$ in argon atmosphere (heating rate of $25^{\circ} \mathrm{C} / \mathrm{h}$ ). Details on the preparation of $\mathbf{C 1 - S i O C - 1 1 0 0}$ are reported in [21].

Thermal treatment of the SiOC glass-ceramics were performed for different durations at temperatures of 1100,1200 and $1300^{\circ} \mathrm{C}$, respectively, in an alumina oven with SiC heating elements using alumina crucibles with a closed lid under air. The applied heating rate was $20^{\circ} \mathrm{C} / \mathrm{min}$ up to $50^{\circ} \mathrm{C}$ below the target temperature, followed by a slower rate of $2{ }^{\circ} \mathrm{C} / \mathrm{min}$ up to the desired annealing temperature. The subsequent cooling was performed at a rate of $10^{\circ} \mathrm{C} / \mathrm{min}$.

Structural characterization. All samples were cut into smaller pieces using a diamond wire cutter and subsequently ground to co-planar geometry. Their chemical composition was 
determined using a carbon analyzer Leco-200 (Leco Corporation,USA) and a N/O analyzer Leco TC-436 (Leco Corporation, USA). The silicon elemental content was calculated as the difference to $100 \mathrm{wt} . \%$, assuming no other elements being present in the samples.

Archimedean (skeletal) density $\rho$ and open porosity were derived upon water immersion technique. Powder X-ray diffraction (XRD) measurements were performed in flat-sample transmission geometry on a STOE STADI P diffractometer (Stoe, Darmstadt, Germany), equipped with a Mo X-ray tube and a position sensitive detector with a $6^{\circ}$ aperture. Raman spectra were recorded on a Horiba HR800 micro-Raman spectrometer (Horiba JobinYvon, Bensheim, Germany), equipped with a He-Ne laser $(\lambda=633 \mathrm{~nm})$. The measurements were conducted by using a grating of $600 \mathrm{~g} / \mathrm{mm}$ and a confocal microscope (magnification $50 \mathrm{x}$ NA0.75 - numerical aperture) with a $100 \mu \mathrm{m}$ aperture, providing a resolution of approximately $1 \mu \mathrm{m}$. The laser power of $20 \mathrm{~mW}$ was attenuated by using neutral density filters.

Assessment of the elastic and plastic deformation behavior. Nanoindentation experiments were carried out on co-planar, optically polished samples using a G200 nanoindenter (Agilent Inc.), equipped with a three-sided Berkovich diamond indenter tip (Synton-MDP Inc.). Before the first experiments, both the tip area function and the instrument's frame compliance were calibrated on a Corning 7980 fused silica reference glass sample (Corning Inc.), following the procedure proposed by Oliver and Pharr [24]. Depth profiles of the Young's modulus $E$ and hardness $H$ were obtained by operating in the continuous stiffness measurement mode [25, $26]$. For statistical relevance, at least ten indentations with a maximum displacement of $2 \mu \mathrm{m}$ were created at a constant strain-rate of $\dot{\varepsilon}=0.05 \mathrm{~s}^{-1}$ (defined as the loading rate $d P / d t$ divided by the actual load $P$ ). The strain-rate sensitivity $m$ was analyzed via a nanoindentation strain-rate jump test as described in detail in Ref. [27]. In total, ten strainrate jump tests with strain-rates of $\dot{\varepsilon}=0.05 ; 0.007$ and $0.001 \mathrm{~s}^{-1}$ (in descending order) were performed. Values of $m$ were derived from the slope of the linear regression between the logarithm of hardness and the logarithm of the indentation strain-rate (defined as the displacement rate $d h / d t$ divided by the actual indentation depth $h$ ) $m=\partial \ln H / \partial \ln \dot{\varepsilon}_{i}$ [28], where $\dot{\varepsilon}_{i}=\dot{\varepsilon} / 2$ for materials with a depth-independent hardness [29]. All nanoindentation experiments were carried out in laboratory air at ambient temperatures of around $301 \pm 3 \mathrm{~K}$ and with thermal drift rates below $0.05 \mathrm{~s}^{-1}$. To avoid interactions between residual stress fields, consecutive indentations were conducted at distances of $50 \mu \mathrm{m}$ [30]. The same samples were subsequently utilized to study the elastic properties through ultrasonic echography with an Echometer 1077 (Karl Deutsch GmbH \& Co. KG, Wuppertal, Germany). Values of the longitudinal $C_{L}$ and transversal sound wave velocities $C_{T}$ were calculated from the corresponding sound wave propagation times, as recorded with an accuracy of \pm 1 ns by piezoelectric transducers operating at frequencies of 8 to $12 \mathrm{MHz}$, divided by the exact thickness of the glass plates, which was determined with an accuracy of $\pm 2 \mu \mathrm{m}$ using a micrometer screw. On that basis, the shear modulus $G$, bulk modulus $K$, and Young's modulus, as well as the Poisson's ratio $v$, were estimated according to the following equations [31]:

$$
G=\rho c_{T}^{2}
$$




$$
\begin{aligned}
& K=\rho\left(c_{L}^{2}-\frac{4}{3} c_{T}^{2}\right) \\
& E=\rho\left[\frac{3 c_{L}^{2}-4 c_{T}^{2}}{\left(c_{L} / c_{T}\right)^{2}-1}\right] \\
& v=\frac{c_{L}^{2}-2 c_{T}^{2}}{2\left(c_{L}^{2}-c_{T}^{2}\right)}
\end{aligned}
$$

In addition, the temperature dependence of the Young's modulus and shear modulus were evaluated using a RFDA (IMCE NV RFDA HT 1050) on co-planar disk-like or rectangular bars with an approximate thickness of $2 \mathrm{~mm}$. Samples were fixed with Pt-Rh wires and heated to $1000{ }^{\circ} \mathrm{C}$ at a rate of $10^{\circ} \mathrm{C} / \mathrm{min}$ in air. The subsequent cooling was carried out at a rate of $10^{\circ} \mathrm{C} / \mathrm{h}$.

The investigation of the samples with both, RFDA and Ultrasonic Echography, requires sufficiently large specimens to be reliably fixed in the device or to detect the signal, respectively. The required minimum sample geometries could not be realized for samples C1-SiOC-1100 (due to the inherent challenges during the polymer-to-ceramic transformation) and $\mathrm{SiC} / \mathrm{SiO}_{2}-1600$ (due to a limited amount of starting material). Consequently, the mentioned two methods were used only for samples meeting the respective requirements (see Table 1 below).

\section{Results and Discussion}

The as-prepared SiOC samples were first analyzed concerning their chemical and phase composition. For a detailed compositional and structural characterization the reader is referred to Refs. [18] and [21]. The monolithic sample pyrolyzed at $1100{ }^{\circ} \mathrm{C}$ (i.e.,

C1-SiOC-1100) is fully X-ray amorphous and consists of an SiOC glass matrix with a homogeneously dispersed phase of $\mathrm{sp}^{2}$-hybridized segregated carbon [5]. The monolithic specimens prepared from hot pressing/FAST at $1600^{\circ} \mathrm{C}$ can be regarded as SiOC glassceramics composed of a vitreous silica matrix with homogeneously dispersed $\beta-\mathrm{SiC}$ nanoparticles and segregated carbon $[5,17,18]$. The phase composition in the system $\mathrm{SiO}_{2}-$ $\mathrm{SiC}-\mathrm{C}$ can be estimated from elemental analysis [6]. The chemical and phase compositions of the samples investigated in the present study are summarized in Table 1 and presented in Figure 1. The volume fractions of $\mathrm{SiO}_{2}$ and $\mathrm{SiC}$ for $\mathbf{C 1 - S i O C - 1 1 0 0}$ can be regarded as the fraction of $\mathrm{Si}-\mathrm{O}$ and $\mathrm{Si}-\mathrm{C}$ bonds, respectively. The volume fraction of $\mathrm{SiC}$ is comparable in all samples. This is also evident from Figure 1, where the compositions investigated in this study lie on a parallel line to the $\mathrm{SiO}_{2}-\mathrm{C}$ tie-line in the $\mathrm{Si}-\mathrm{O}-\mathrm{C}$ ternary phase diagram. No segregated carbon was noticed in the $\mathbf{S i C} / \mathbf{S i O}_{2}-\mathbf{1 6 0 0}$ sample. By comparing $\mathbf{C 1 - S i O C - 1 1 0 0}$ with C1-SiOC-1600, it can be concluded that the phase separation has no influence on the overall chemical composition (e.g., through volatilization). 
Table 1. Chemical compositions of the monolithic SiOC samples, their estimated phase compositions and the corresponding skeletal densities $\rho$. Volume fractions of $\mathrm{SiO}_{2}, \mathrm{SiC}$ and segregated carbon $\mathrm{C}_{\text {segr }}$ are calculated by means of the following densities: $\rho\left(\mathrm{SiO}_{2}\right)=2.20 \mathrm{~g} / \mathrm{cm}^{3}[15], \rho(\beta-\mathrm{SiC})=3.22 \mathrm{~g} / \mathrm{cm}^{3}$ [32], $\rho\left(\mathrm{C}_{\text {segr }}\right)=1.82 \mathrm{~g} / \mathrm{cm}^{3}$ (Graphitized Mesoporous Carbons GMC, Sigma-Aldrich, CAS-\# 1333-86-4).

\begin{tabular}{|c|c|c|c|c|c|c|c|c|}
\hline \multirow{2}{*}{ Sample } & \multirow{2}{*}{$\begin{array}{l}\text { Empirical } \\
\text { Formulae }\end{array}$} & \multicolumn{3}{|c|}{ Phase Composition [mol\%] } & \multicolumn{3}{|c|}{ Phase Composition [vol.\%] } & \multirow{2}{*}{$\begin{array}{l}\text { Density } \rho \\
{\left[\mathrm{g} / \mathrm{cm}^{3}\right]}\end{array}$} \\
\hline & & $\mathrm{SiO}_{2}$ & SiC & $\mathrm{C}_{\text {segr }}$ & $\mathrm{SiO}_{2}$ & $\mathrm{SiC}$ & $\mathrm{C}_{\text {segr }}$ & \\
\hline $\begin{array}{l}\text { C1-SiOC-1100 } \\
\text { [21] }\end{array}$ & $\mathrm{SiO}_{1.38} \mathrm{C}_{0.32}$ & $\begin{array}{l}68.11 \\
\pm 1.1\end{array}$ & $\begin{array}{l}30.71 \\
\pm 2.3\end{array}$ & $\begin{array}{l}1.2^{1} \\
\pm 0.5\end{array}$ & $\begin{array}{l}81.7^{2} \\
\pm 1.3\end{array}$ & $\begin{array}{l}17.9^{2} \\
\pm 1.3\end{array}$ & $\begin{array}{l}0.4^{2} \\
\pm 0.9\end{array}$ & 2.28 \\
\hline $\begin{array}{l}\mathrm{SiC} / \mathrm{SiO}_{2}-1600 \\
{[18]}\end{array}$ & $\mathrm{SiO}_{1.47} \mathrm{C}_{0.24}$ & 73.2 & 26.8 & 0 & 85.7 & 14.3 & 0 & 2.36 \\
\hline $\begin{array}{l}\text { C1-SiOC-1600 } \\
\text { [21] }\end{array}$ & $\mathrm{SiO}_{1.41} \mathrm{C}_{0.30}$ & $\begin{array}{l}70.2 \\
\pm 0.5\end{array}$ & $\begin{array}{l}29.3 \\
\pm 2.1\end{array}$ & $\begin{array}{l}0.5 \\
\pm 2.7\end{array}$ & $\begin{array}{l}83.0 \\
\pm 0.6\end{array}$ & $\begin{array}{l}16.8 \\
\pm 1.2\end{array}$ & $\begin{array}{l}0.2 \\
\pm 0.8\end{array}$ & 2.38 \\
\hline $\begin{array}{l}\text { C12-SiOC-1600 } \\
\text { [21] }\end{array}$ & $\mathrm{SiO}_{1.50} \mathrm{C}_{0.71}$ & $\begin{array}{l}51.3 \\
\pm 0.3\end{array}$ & $\begin{array}{l}17.2 \\
\pm 1.4\end{array}$ & $\begin{array}{l}31.5 \\
\pm 1.7\end{array}$ & $\begin{array}{l}75.7 \\
\pm 0.4\end{array}$ & $\begin{array}{l}12.3 \\
\pm 1.0\end{array}$ & $\begin{array}{l}11.9 \\
\pm 0.7\end{array}$ & 2.31 \\
\hline $\begin{array}{l}\text { C16-SiOC-1600 } \\
{[21]}\end{array}$ & $\mathrm{SiO}_{1.27} \mathrm{C}_{0.97}$ & $\begin{array}{l}39.6 \\
\pm 1.1\end{array}$ & $\begin{array}{l}22.8 \\
\pm 1.7\end{array}$ & $\begin{array}{l}37.6 \\
\pm 1.7\end{array}$ & $\begin{array}{l}65.7 \\
\pm 1.9\end{array}$ & $\begin{array}{l}18.3 \\
\pm 1.3\end{array}$ & $\begin{array}{l}16.0 \\
\pm 0.7\end{array}$ & 2.34 \\
\hline
\end{tabular}

${ }^{1}$ Molar fractions of $\mathrm{SiO}_{2}$ and $\mathrm{SiC}$ can be regarded as the fraction of Si-O and Si-C bonds, respectively.

${ }^{2}$ Volume fractions of $\mathrm{SiO}_{2}$ and $\mathrm{SiC}$ can be regarded as the fraction of $\mathrm{Si}-\mathrm{O}$ and $\mathrm{Si}-\mathrm{C}$ bonds, respectively. Absolute values are expected to be shifted due to unknown density of the disordered arrangement of $\mathrm{SiC}_{4}$ tetrahedra.

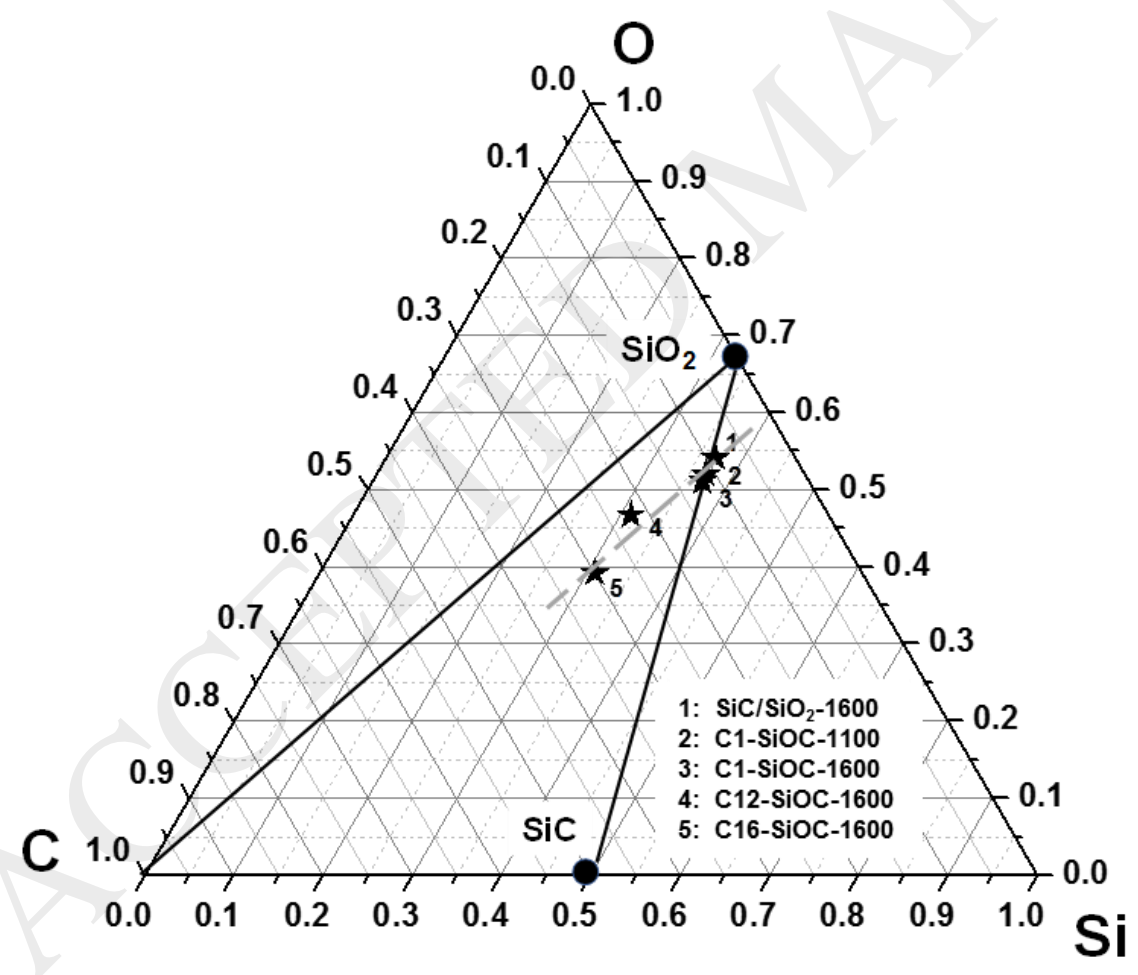

Figure 1. Ternary phase diagram in the system Si-O-C. The dashed line (parallel to the $\mathrm{SiO}_{2}-\mathrm{C}$ tieline) marks that the segregated carbon content increases from $\mathrm{SiC} / \mathrm{SiO}_{2}-\mathbf{1 6 0 0}$ to $\mathbf{C 1 6}$ -

SiOC-1600 without large variations in the $\mathrm{SiC}$ content.

The skeletal densities of the investigated SiOC samples are summarized in Table 1.

Replacing oxygen in the $\mathrm{SiO}_{2}$ network by carbon leads to an increase in density from 2.20 up to $2.28 \mathrm{~g} / \mathrm{cm}^{3}$ in the $\mathbf{C 1 - S i O C - 1 1 0 0 ~ g l a s s ~ s p e c i m e n . ~ T h e ~ f u r t h e r ~ i n c r e a s e ~ i n ~ d e n s i t y ~ f r o m ~} 2.28$ 
bending or indentation experiments display relatively large standard deviations [10, 14, 33]. However, a rough tendency is discernable in Figure 2a, that Young's modulus in SiOC glasses and glass-ceramics decreases with increasing content of $\mathrm{sp}^{2}$-hybridized segregated carbon. While the $\mathbf{C 1 - S i O C - 1 1 0 0}$ glass sample with only 1 vol.\% of $\mathrm{sp}^{2}$-hybridized segregated carbon investigated in this study exhibits a Young's modulus of $101.7 \mathrm{GPa}$, a much lower Young's modulus of only $66 \mathrm{GPa}$ has previously been reported for a SiOC glass with approximately 64 vol.\% of segregated carbon [38].
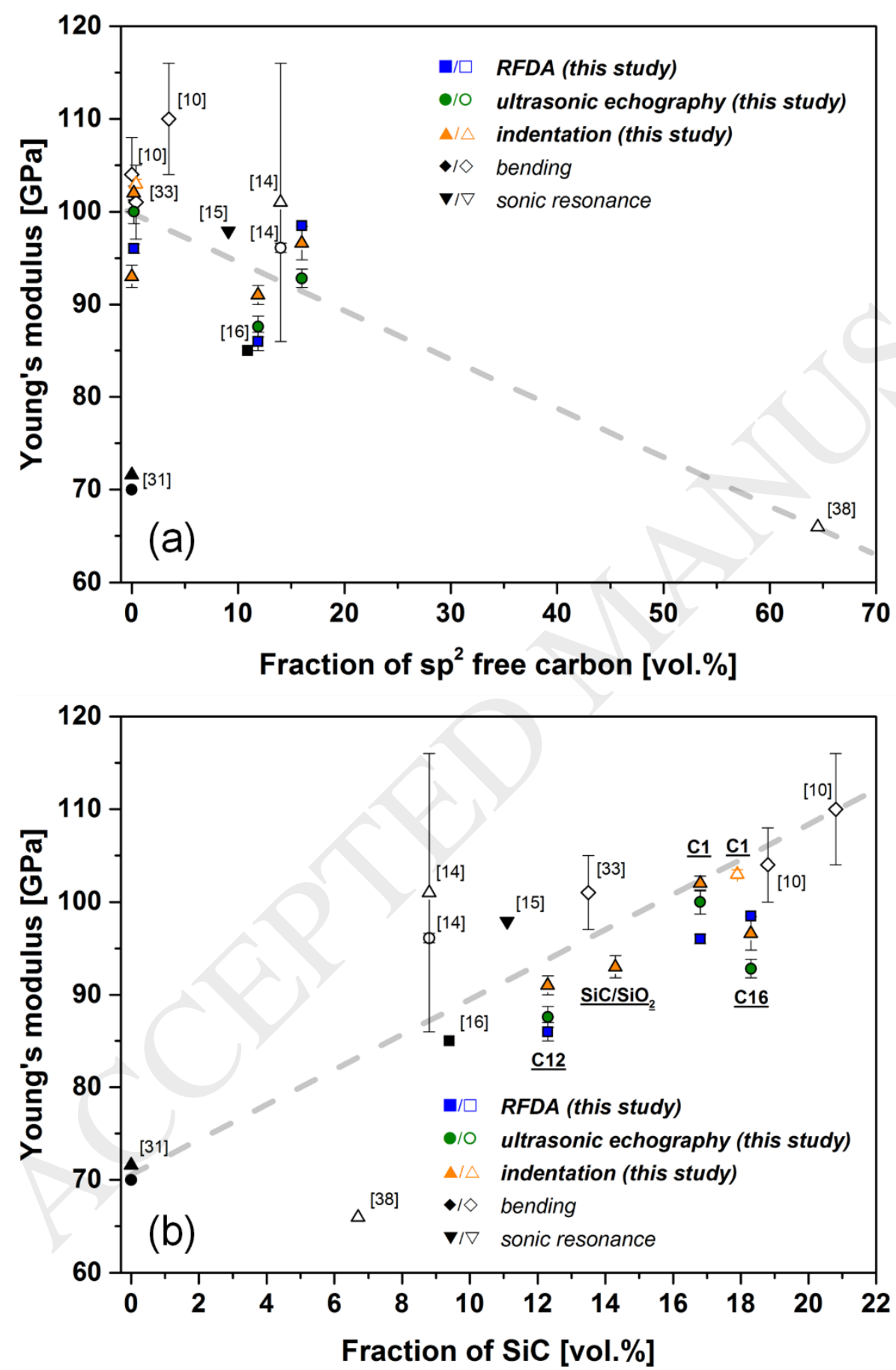

Figure 2. Room temperature Young's modulus of SiOC glasses (open symbols) and glassceramics (filled symbols) as a function of (a) volume fraction of $\mathrm{sp}^{2}$-hybridized segregated carbon and (b) the volume fraction of Si-C bonds (as for SiOC glasses) or B-SiC (as for $\mathrm{SiOC}$ glass-ceramics). Literature values (black symbols) are added for comparison. Dashed lines were drawn as a guide for the eyes. 
A plot of Young's modulus against the volume fraction of $\mathrm{SiC}$ in Figure $2 \mathrm{~b}$ (for $\mathrm{SiOC}$ glasses, the volume fraction of $\mathrm{SiC}$ is thought to be systematically shifted to lower values due to the unknown density of the disordered arrangement of $\mathrm{SiC}_{4}$ tetrahedra) reveals their direct interrelation. SiOC materials with a larger fraction of SiC typically exhibit a higher Young's modulus as compared to samples containing a smaller fraction of $\mathrm{SiC}$. This result is supposed to be related to the high values of $E=300 \mathrm{GPa}$ of the nano-sized $\beta$-SiC precipitates [37]. Thus, $\mathrm{sp}^{2}$-hybridized segregated carbon and $\beta$-SiC nanoparticles have the opposite effect on Young's modulus of SiOC glasses and glass-ceramics. This dependency was already suggested by Soraru et al. for a significantly smaller compositional range of SiOC glasses and for thin films [10,39] and is extended now in this study to bulk SiOC glasses with higher amounts of segregated carbon and monolithic SiOC glass-ceramics.

Figure 3 illustrates the temperature dependence of Young's modulus of the investigated SiOC glass-ceramics with 1, 12 and 16 vol.\% of segregated carbon, respectively. All samples are characterized by an increasing Young's modulus with increasing temperature. It is known from literature that Young's modulus of SiOC glasses and glass-ceramics increases with temperature (i.e. stiffening) analogous to vitreous silica [11, 16, 40]. In the case of vitreous silica, this behavior has been attributed to continuous atomic displacements during an amorphous-amorphous transformation comparable to the structural rearrangements associated to the $\alpha$ - to $\beta$-cristobalite phase transition in crystalline $\mathrm{SiO}_{2}[34,41]$. We therefore conclude that the temperature dependence of the Young's modulus in the present SiOC glass-ceramics is dominated by the silica glass matrix. Since the Young's modulus did not show any hysteresis effects during cooling (not shown here), irreversible changes during the measurements can be excluded.

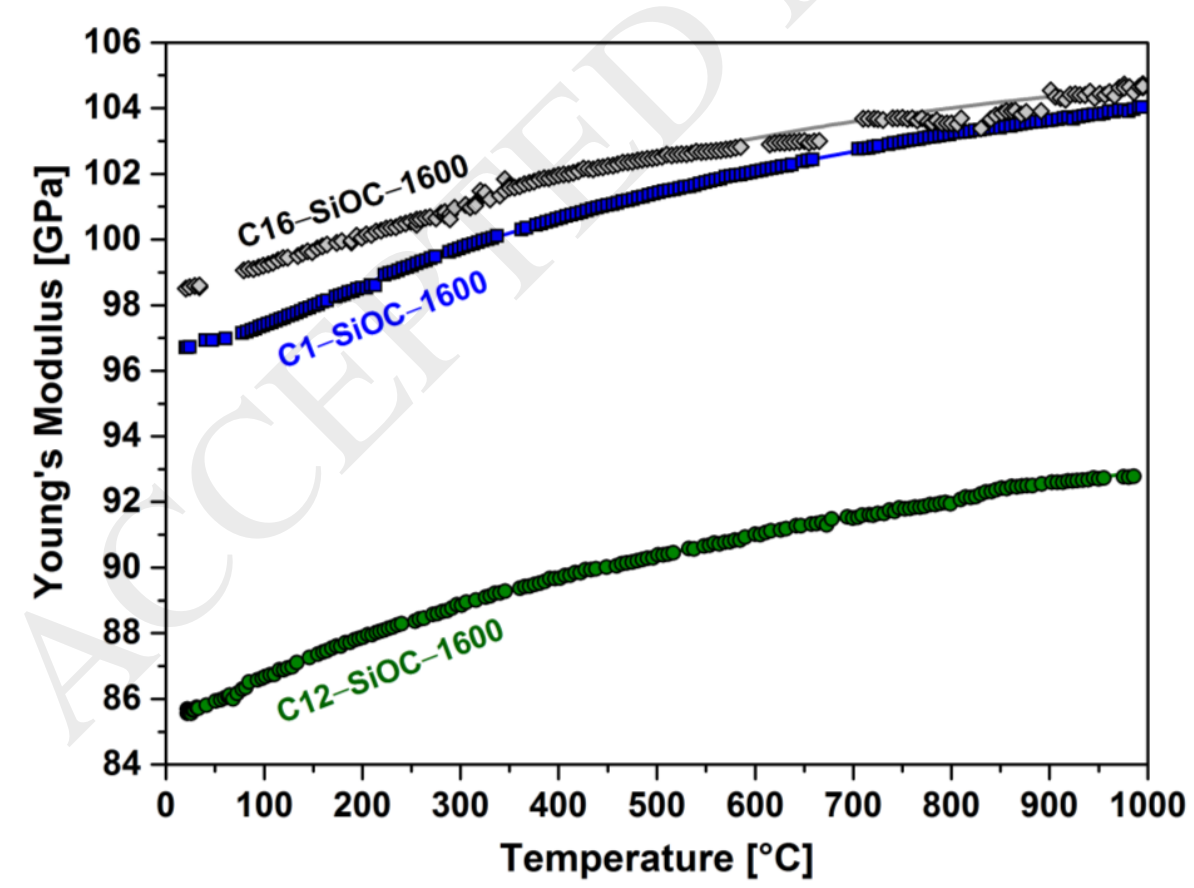

Figure 3. Temperature dependence of the Young's modulus of the SiOC glass-ceramics investigated in this study. The experimental error is estimated to be $\pm 1 \mathrm{GPa}$ (i.e., $<2 \%$ ). 
Depending on the respective length scale, several different factors may affect the Young's modulus of glasses, including the atomic bonding energy and packing density, but also the network connectivity [34] and super-structural heterogeneity [42, 43]. Consequently, the stability of a glass, e.g., upon exposure to high temperatures can be monitored well by the measurement of Young's modulus, as a change in Young's modulus would be caused by a change in one or more of the above-mentioned structural parameters.

Thus, in the present study, Young's modulus was used to identify possible structural changes (i.e. decomposition or crystallization of the amorphous matrix) occurring in SiOC glassceramics (prepared at $1600^{\circ} \mathrm{C}$; i.e., fully phase-separated) which may result from their thermal annealing, for example during high-temperature creep experiments. Annealing temperatures and holding times were chosen according to the time necessary to reach the steady-state regime (secondary creep) in creep experiments, as previously reported [19]. For sample C1-SiOC-1600, the chosen annealing conditions were 6 days at $1100{ }^{\circ} \mathrm{C}$ and 2 hours at $1300{ }^{\circ} \mathrm{C}$, respectively, while for samples C12-SiOC-1600 and C16-SiOC-1600 the conditions were 6 days at $1200^{\circ} \mathrm{C}$ and 12 hours at $1300^{\circ} \mathrm{C}$, respectively. Figures $4 \mathrm{a}-\mathrm{C}$ show the temperature evolution of Young's modulus before and after annealing at the chosen conditions. All SiOC glass-ceramics exhibit an increase in Young's modulus after annealing, where the annealing at higher temperature leads to a larger increase. In comparison to the as-prepared sample, C1-SiOC-1600 shows the lowest total increase of Young's modulus of about $1.4 \%$; whereas C12-SiOC-1600 exhibits an increase of about $7.3 \%$. C16-SiOC-1600 shows the highest total increase of the Young's modulus (approximately $8.8 \%$ at $1200{ }^{\circ} \mathrm{C}$ ). Interestingly, C16-SiOC-1600 shows lower Young's modulus (and its increase) during the thermal annealing at $1300^{\circ} \mathrm{C}$ as compared to the features recorded during annealing at $1200^{\circ} \mathrm{C}$ (see Figure 4c). The SiOC glass-ceramics are already fully phase-separated (i.e. the evolution of $\beta-S i C$ nanoparticles occurred already during synthesis). Consequently, this increase in Young's modulus cannot be attributed to the precipitation of $\beta-\mathrm{SiC}$ nanoparticles.

In order to further rationalize the increase in Young's modulus and to directly compare all investigated samples, Figure 4d displays the temperature-dependent Young's modulus normalized to the corresponding value at room temperature of the investigated SiOC glassceramics (as-prepared and after thermal annealing). The temperature sensitivity of Young's modulus, i.e. the evolution of Young's modulus with temperature, is not affected by thermal annealing, as the curves of the individual glass-ceramics are identical within the estimated accuracy of the measurement $( \pm 1 \mathrm{GPa} ;<2 \%)$. The temperature sensitivity can be correlated to the fragility of glasses [44]. Furthermore, the fragility of glasses is connected to their atomic packing density, where glasses with high atomic packing density are known to be more fragile [45]. Consequently, the stable temperature sensitivity indicates, that the glassy matrix of the investigated SiOC glass-ceramics is not significantly affected by thermal annealing. 

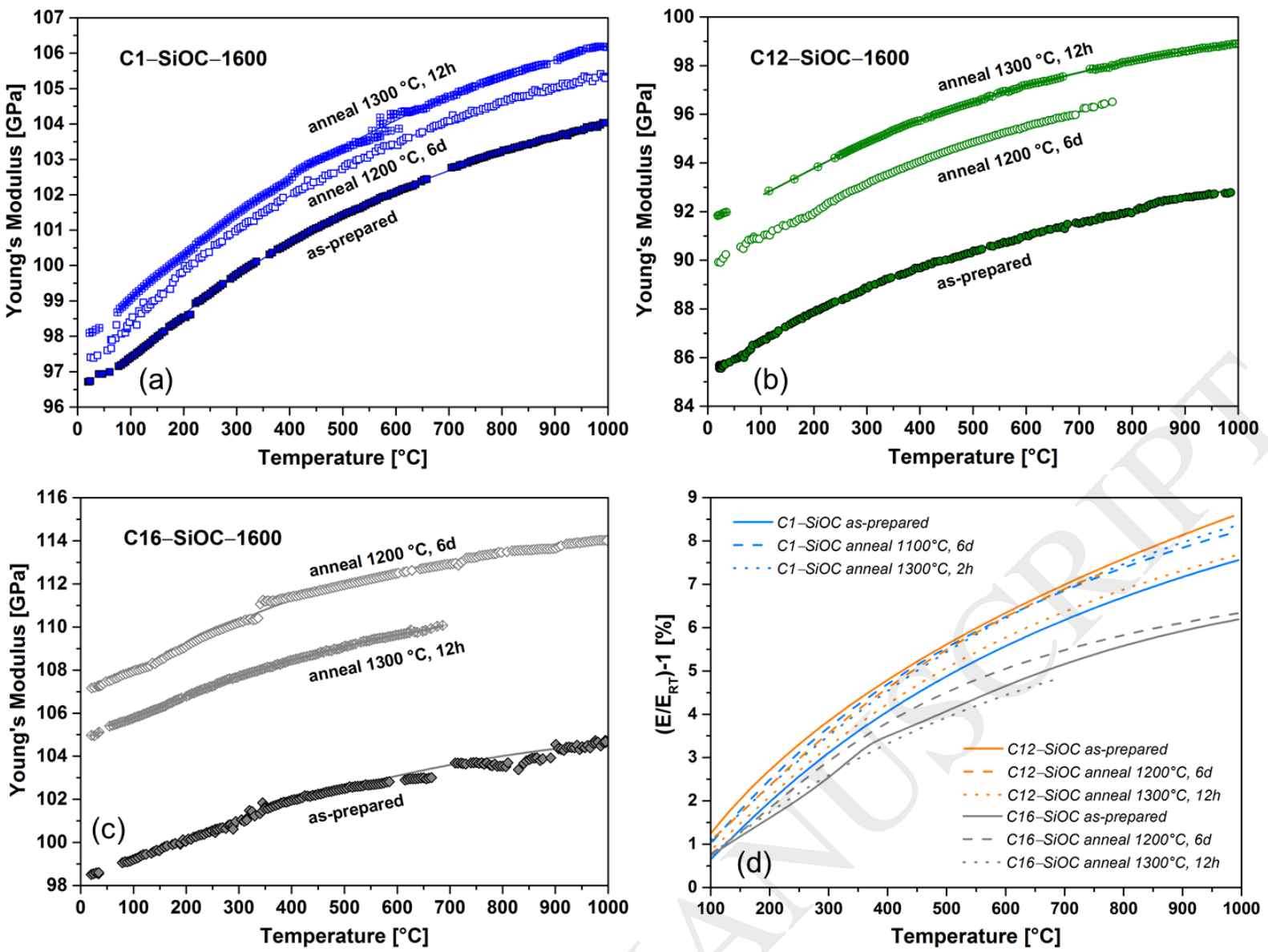

Figure 4. Temperature dependence of the Young's modulus of the as-prepared (a) C1-SiOC-1600, (b) C12-SiOC-1600 and (c) C16-SiOC-1600 SiOC glass-ceramics, respectively, and after a thermal treatment at different temperatures and for varying durations. Lines drawn are fits to the experimental data. (d) Temperature dependence of the Young's modulus normalized to its value at room temperature (displayed by trendlines). The experimental error is estimated to be $\pm 1 \mathrm{GPa}$ (i.e., $<2 \%$ ).

Table 3. Skeletal density $\rho$ and elemental composition of the investigated as-prepared SiOC glassceramics and after a thermal treatment.

\begin{tabular}{|c|c|c|c|c|c|c|}
\hline \multirow{2}{*}{ Sample } & \multirow{2}{*}{$\begin{array}{l}\text { Annealing } \\
\text { Conditions }\end{array}$} & \multirow{2}{*}{$\begin{array}{l}\text { Density } \rho \\
{\left[\mathrm{g} / \mathrm{cm}^{3}\right]}\end{array}$} & \multirow{2}{*}{$\begin{array}{l}\text { Weight } \\
\text { loss [\%] }\end{array}$} & \multicolumn{3}{|c|}{ Elemental Composition } \\
\hline & & & & Si [wt.\%] & O [wt.\%] & C [wt.\%] \\
\hline \multirow{3}{*}{ C1-SiOC-1600 } & as-prepared & $2.38^{*}$ & - & $51.78^{*}$ & $41.59^{*}$ & $6.63^{*}$ \\
\hline & $1100^{\circ} \mathrm{C}, 6 \mathrm{~d}$ & 2.38 & 1.66 & 52.66 & 40.57 & 6.77 \\
\hline & $1300^{\circ} \mathrm{C}, 2 \mathrm{~h}$ & 2.38 & - & 52.54 & 40.59 & 6.87 \\
\hline \multirow{3}{*}{ C12-SiOC-1600 } & as-prepared & $2.31^{*}$ & - & $46.36^{*}$ & $39.52^{*}$ & $14.12^{*}$ \\
\hline & $1200^{\circ} \mathrm{C}, 6 \mathrm{~d}$ & 2.32 & 0 & 47.48 & 38.97 & 13.55 \\
\hline & $1300^{\circ} \mathrm{C}, 12 \mathrm{~h}$ & 2.32 & 0 & 46.81 & 39.32 & 13.87 \\
\hline \multirow{3}{*}{ C16-SiOC-1600 } & as-prepared & $2.34^{*}$ & - & $46.79^{*}$ & $33.82^{*}$ & $19.39^{*}$ \\
\hline & $1200^{\circ} \mathrm{C}, 6 \mathrm{~d}$ & 2.37 & 0.14 & 47.35 & 33.56 & 19.09 \\
\hline & $1300^{\circ} \mathrm{C}, 12 \mathrm{~h}$ & 2.38 & 0.19 & 46.89 & 33.66 & 19.45 \\
\hline
\end{tabular}

*Values taken from Ref. [21]

In general, two main strategies for improving Young's modulus for specific glass series are discussed in glass science: (i) an increase in the atomic packing density and (ii) an increase 
in the local bond strength [34]. Both do not apply for our SiOC glass-ceramics. The first is expected to be related to an increase in the skeletal density and the second relies on a change in the elemental composition. For the investigated SiOC samples, the skeletal densities remain constant and consequently the first effect can be ruled out. Moreover, as the samples show only negligible weight loss and changes in their elemental composition (Table 3), also the second effect can be excluded. Consequently, the increase of Young's modulus if $\mathrm{SiOC}$ glass-ceramics after thermal annealing should have other origin and further supports the stability of the glassy matrix as already discussed considering the temperature sensitivity. One possible effect may arise from crystallization processes of the dispersed phases in SiOC glass-ceramics which take place during thermal annealing.

It is known that Young's moduli of nanocrystalline materials are significantly lower than those of their crystalline counterparts [37]. Consequently, it is expected that an increased ordering /crystallization of the $\beta-\mathrm{SiC}$ nanoparticles or the segregated carbon phase in our SiOC samples might explain the observed increase in their Young's moduli. The evolution of the $\mathrm{sp}^{2}$-hybridized carbon phase in the SiOC glass-ceramics was studied by Raman spectroscopy, which may provide information on the average crystallite size $L_{a}$ and the average distance between two defects $L_{D}$ in the segregated carbon phase. The procedure used for the determination of $L_{a}$ and $L_{D}$ from the intensity ratio between $D$ and $G$ band (typical features in Raman spectra of disordered carbons) in silicon oxycarbides is described in detail in [21] and values of the investigated samples are summarized in Table 4 . Both $L_{a}$ and $L_{D}$ are slightly increased in C1-SiOC-1600 and C16-SiOC-1600 after annealing at 1200 ${ }^{\circ} \mathrm{C}$ for 6 days; whereas, they were rather indifferent to the annealing experiment at $1300{ }^{\circ} \mathrm{C}$ for 12 hours. This indicates some increased ordering of the segregated carbon phase during the long-term annealing at $1200^{\circ} \mathrm{C}$, which may though explain the increase of the Young's modulus in SiOC after annealing.

Table 4. Effects of a thermal treatment on the degree of graphitization of the segregated carbon in SiOC glass-ceramics as determined from Raman spectroscopy: Average crystallite size $L_{a}$, average distance between two defects $L_{D}$. $A_{D} / A_{G}$ describes the ratio between the areas assigned to the $D$ and $G$ band, respectively.

\begin{tabular}{lllll}
\hline Sample & $\begin{array}{l}\text { Annealing } \\
\text { conditions }\end{array}$ & $\mathbf{A}_{\mathrm{D}} / \mathbf{A}_{\mathrm{G}}$ & $\mathrm{L}_{\mathrm{a}}[\mathrm{nm}]$ & $\mathrm{L}_{\mathrm{D}}[\mathrm{nm}]$ \\
\hline \multirow{3}{*}{ C1-SiOC-1600 } & as prepared & $3.185 \pm 0.233$ & $12.1 \pm 0.9$ & $9.5 \pm 0.4$ \\
& $1100^{\circ} \mathrm{C}, 6 \mathrm{~d}$ & $2.800 \pm 0.142$ & $13.8 \pm 0.7$ & $10.2 \pm 0.3$ \\
& $1300^{\circ} \mathrm{C}, 12 \mathrm{~h}$ & $2.232 \pm 0.356$ & $17.3 \pm 2.7$ & $11.4 \pm 0.9$ \\
\hline \multirow{3}{*}{ C12-SiOC-1600 } & as prepared & $4.215 \pm 0.251^{*}$ & $9.2 \pm 0.6^{*}$ & $8.3 \pm 0.3^{*}$ \\
& $1200^{\circ} \mathrm{C}, 6 \mathrm{~d}$ & $4.539 \pm 0.422$ & $8.5 \pm 0.8$ & $8.0 \pm 0.4$ \\
& $1300^{\circ} \mathrm{C}, 12 \mathrm{~h}$ & $4.699 \pm 0.036$ & $8.2 \pm 0.1$ & $7.8 \pm 0.1$ \\
\hline \multirow{3}{*}{ C16-SiOC-1600 } & as prepared & $4.121 \pm 0.521^{*}$ & $9.5 \pm 1.3^{*}$ & $8.4 \pm 0.6^{*}$ \\
& $1200^{\circ} \mathrm{C}, 6 \mathrm{~d}$ & $3.093 \pm 0.203$ & $12.5 \pm 0.8$ & $9.7 \pm 0.3$ \\
& $1300^{\circ} \mathrm{C}, 12 \mathrm{~h}$ & $4.104 \pm 0.075$ & $9.4 \pm 0.2$ & $8.4 \pm 0.1$ \\
\hline
\end{tabular}

*Values are taken from Ref. [21]

In addition to the $\mathrm{sp}^{2}$-hybridized carbon phase, the $\beta-\mathrm{SiC}$ nanoparticles may also be subjected to crystallization during the high-temperature annealing process. Figure 5 shows 
the XRD patterns of the SiOC glass-ceramics before and after thermal annealing. There is no indication for the crystallization of cristobalite. The presence of a reflection at $2 \theta=11.5^{\circ}$ for samples C16-SiOC-1600 annealed at $1200^{\circ} \mathrm{C}$ for 6 days and C12-SiOC-1600 annealed at $1300{ }^{\circ} \mathrm{C}$ for 12 hours may be considered as an indication for the presence of the segregated carbon phase [46]. This is in good agreement with the observed increase of $L_{\mathrm{a}}$ and $L_{\mathrm{D}}$ as determined by Raman spectroscopy for C16-SiOC-1600. Differences between XRD and $L_{a}$ and $L_{D}$ as determined from Raman spectroscopy for sample C12-SiOC-1600 are due to different volumes accessible for both measurement techniques, where powder XRD gives an averaged picture of the top layer of the whole sample, whereas Raman spectroscopy gives a localized information of low lateral size.
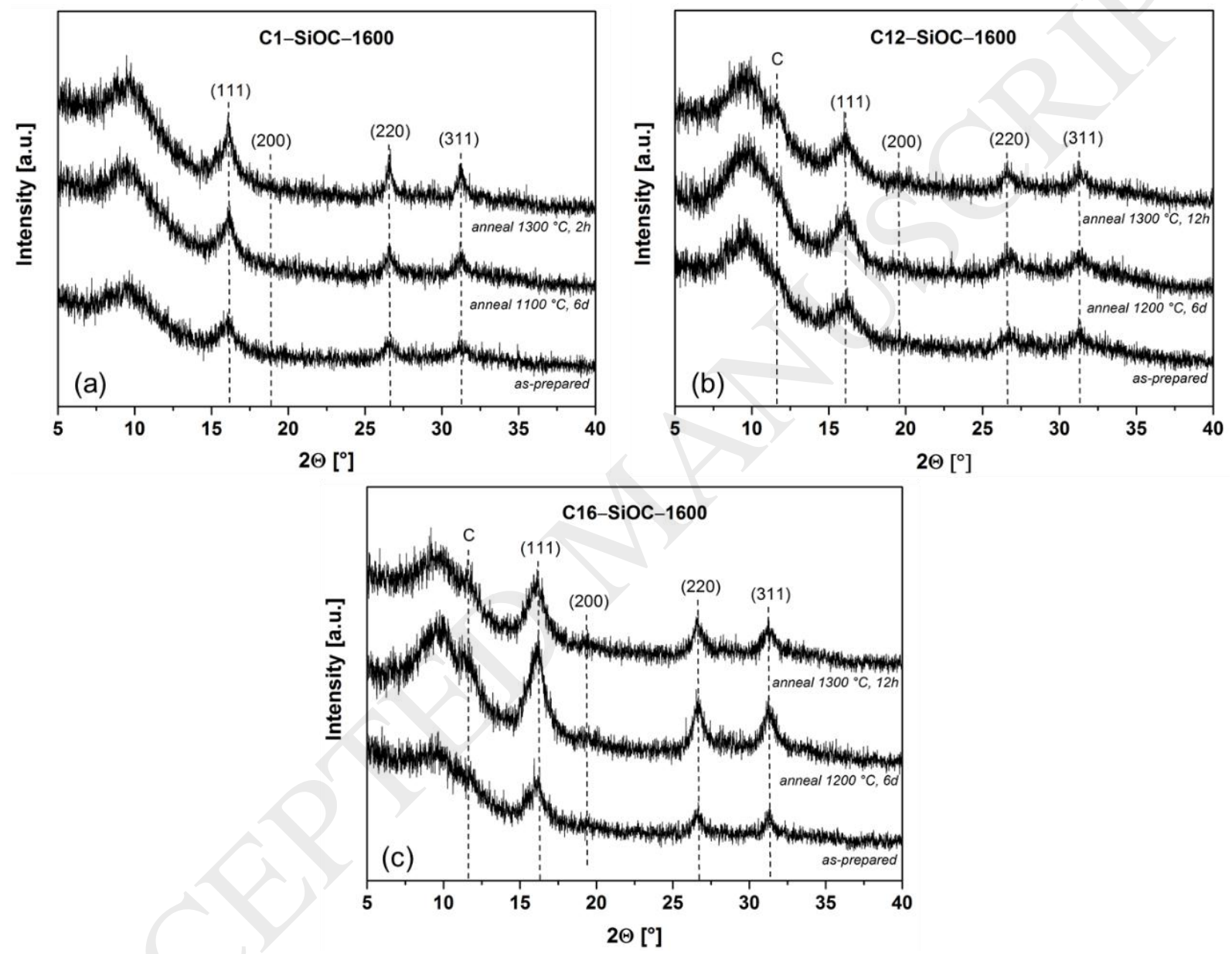

Figure 5. X-ray diffraction patterns (Mo $\left.\mathrm{K}_{\alpha}\right)$ of SiOC glass-ceramics prior and after annealing at high temperatures: (a) C1-SiOC-1600; (b) C12-SiOC-1600; (c) C16-SiOC-1600. Indexed reflections relate to $\beta-\mathrm{SiC}$.

Additionally, slight changes in the shape of the reflections related to $\beta$-SiC after thermal annealing can be identified. Rietveld refinement was performed with fixed lattice parameters. Crystallite size and micro-strain were refined according to the recommendations given in [47], with both Lorentzian and Gaussian contributions. For C1-SiOC-1600, a slight increase in average crystallite size of 2.2 to $3.1 \mathrm{~nm}$ and an increase in scale factor of about $20 \%$ was determined after thermal annealing, indicating two effects caused by the high-temperature treatment of SiOC glass-ceramics. Firstly, an increase of the crystallite size of $\beta$-SiC reflects better ordering thereof. Secondly, an increase in scale factor relates to an increase of the 
amount of $\beta$-SiC, which in the present case can be explained either by the segregation of additional $\beta$-SiC during the thermal annealing (which would imply an incomplete phase separation of the SiOC glass during the hot-pressing step while preparing the monolithic glass-ceramics) or by the crystallization (i.e., increase in size) of precipitates that were too small to be reliably distinguished from the background of the XRD patterns (and are consequently not included in the scale factor for $\beta-\mathrm{SiC}$ ). In other words, the increase of the scale factor is correlated to the crystallization of $\mathrm{x}$-ray amorphous $\mathrm{SiC}$ to nanocrystalline $\beta$ $\mathrm{SiC}$.

For C12-SiOC-1600 and C16-SiOC-1600, thermal annealing leads to a significant increase of the scale factor (ca. $200 \%$ at maximum), accompanied by a slight decrease in the average crystallite sizes from 2.6-2.8 to $1.7-2.3 \mathrm{~nm}$. The strong increase of the scale factor implies that there is a significant amount of X-ray amorphous $\mathrm{SiC}$ in the as-prepared monolithic SiOC glass-ceramics which crystallizes during the high-temperature annealing. At the same time, nanocrystalline $\beta$-SiC nanoparticles increase in size, too. Interestingly, as the amount of X-ray amorphous $\mathrm{SiC}$ nanoparticles which crystallizes is significant, there is an overall decrease of the average crystallite size after the thermal annealing.

From the above, it can be concluded that there is an increased ordering of $\beta-\mathrm{SiC}$ in all three samples upon thermal annealing (it is noted that the Rietveld refinement on the available data of such kind of disordered materials has to be regarded as being semi-quantitative and absolute values may be shifted). The most noticeable change is observed in C16-SiOC-1600 annealed at $1200^{\circ} \mathrm{C}$ for 6 days. This is in line with the highest increase in Young's modulus and the highest carbon content. As it is suggested in literature that the presence of segregated carbon slows down $\beta$-SiC crystallization $[5,48]$, the as-prepared C16-SiOC-1600 sample is the least ordered sample with respect to $\beta-\mathrm{SiC}$ nanoparticles, and shows therefore the highest changes during thermal annealing. It is consequently suggested, that this increased ordering of the $\beta-\mathrm{SiC}$ nanoparticles is sufficient for an increase in Young's modulus, however, not high enough to be detectable at the scale of the skeletal density. As crystallization is a thermally activated process, higher temperatures and holding times favor higher degree of ordering and consequently Young's modulus. This can as well explain the relatively large increase in Young's modulus of C12-SiOC-1600 and C16-SiOC-1600 in comparison to C1-SiOC-1600. Thus, the effect of the $\beta$-SiC crystallization in SiOC-based glass-ceramics on their Young's modulus is significantly higher than that of their chemical composition. 
The temperature dependencies of shear modulus, G, and Poisson's ratio, $v$, determined for C1-SiOC-1600 prior and post thermal annealing are shown in Figure 6
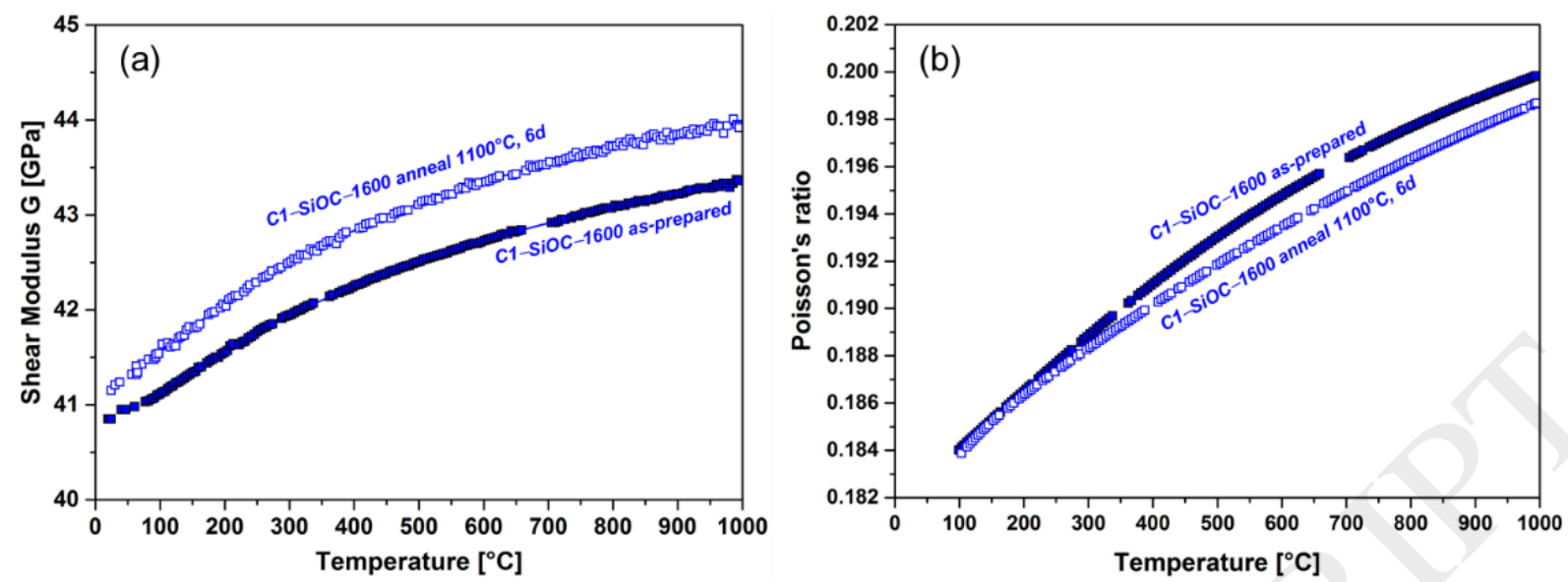

Figure . In accordance to the evolution of Young's modulus, both shear modulus and Poisson's ratio are increasing with increasing temperature. This indicates that the mechanisms leading to a stiffening during temperature increase are at least partially resulting from an increase of the atomic packing density (as expressed by changes in Poisson's ratio), which is in line with the suggested structural rearrangements in vitreous silica [34, 41]. Thermal annealing leads to a slight increase of the shear modulus, however within the estimated experimental error of $\pm 1 \mathrm{GPa}$. Poisson's ratio is not significantly impaired by thermal annealing as evidenced by comparing the values of $v$ before and after annealing at $1100{ }^{\circ} \mathrm{C}$ for 6 days. Poisson's ratio correlates to the atomic packing density, as will be addressed in the following, which in turn is expected to be mainly governed by the glassy matrix in a glass-ceramic. As Poisson's ratio of SiOC glass-ceramics is not significantly affected by the thermal treatment protocols, it is concluded that their silica-based amorphous matrix does not change during thermal annealing, indicating a good thermal stability of SiOC glass-ceramics.
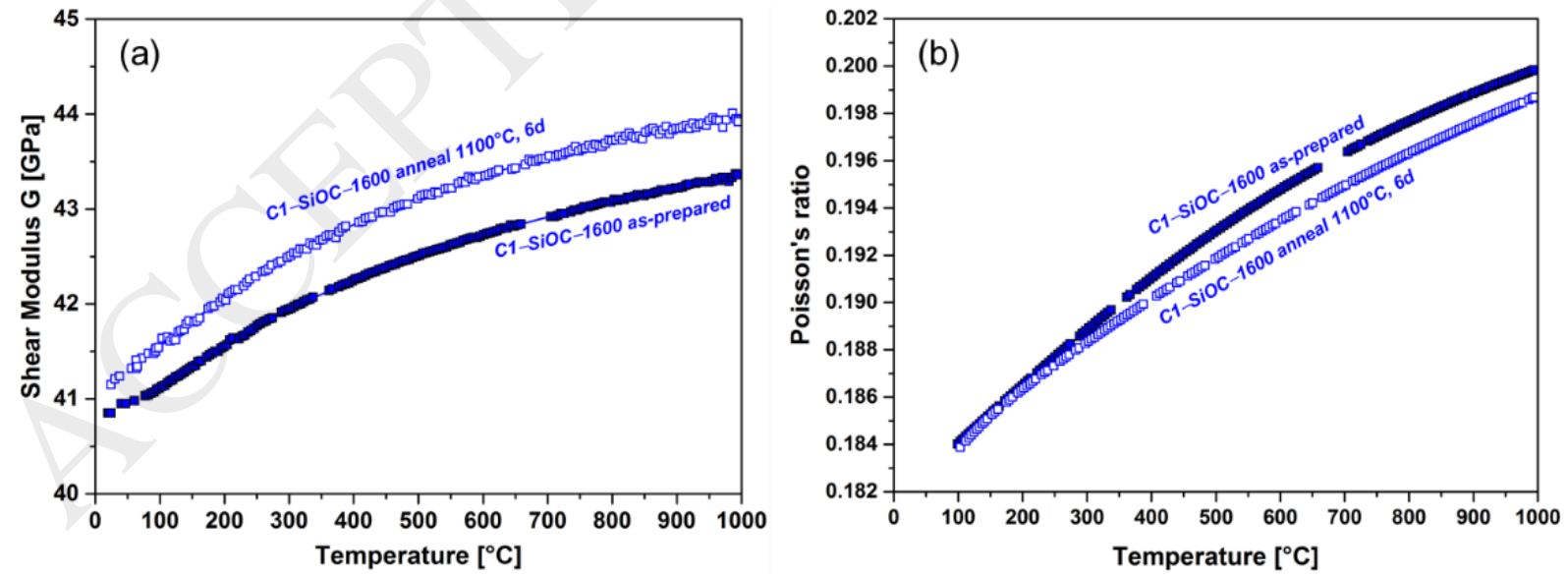

Figure 6. Temperature dependence of the shear modulus $G$ and Poisson's ratio $v$ of the (a) asprepared C1-SiOC-1600 SiOC glass-ceramic and (b) after a thermal treatment for 6 days at $1100^{\circ} \mathrm{C}$

Values of the Young's modulus, shear modulus, bulk modulus, Poisson's ratio, hardness and strain-rate sensitivity at room temperature are summarized in Table 2. Poisson's ratio of the SiOC glass-ceramics are virtually independent on their phase composition. The values of $v$ 
as determined by ultrasonic echography scatter only slightly within a narrow interval of 0.166 to 0.175 , which compares very well with the range of Poisson ratios reported for vitreous silica of 0.15 to 0.18 [27, 49-53]. Interestingly, a SiOC glass derived from the same polymeric precursor as the $\mathbf{C 1 2 - S i O C - 1 6 0 0 ~ g l a s s - c e r a m i c ~ w a s ~ f o u n d ~ t o ~ e x h i b i t ~ a n ~ e x t r e m e l y ~ l o w ~}$ Poisson's ratio of only 0.11 [14]. Smaller Poisson's ratios in glasses are often correlated to strongly interconnected network structures of low atomic packing density [34, 54]. In case of SiOC glass, this is explained by the enhanced degree of cross-linking upon the exchange of two-fold coordinated oxygen atoms with four-fold coordinated carbon. The significantly higher Poisson's ratios of the SiOC glass-ceramics investigated in the present study are linked to the phase separation in SiOC glasses at temperatures exceeding $1250^{\circ} \mathrm{C}[7,9]$. We therefore conclude, that the Poisson ratio of our SiOC glass-ceramics are determined by the elastic properties of residual silica glass matrix.

The hardness of the studied SiOC glass and glass-ceramics scatter slightly around 10.5 to 11.4 GPa. The higher hardness of the $\mathbf{C} 1-$ SiOC-1100 glass $(H=11.4 \mathrm{GPa})$ in comparison to vitreous silica ( $H=9.3 \mathrm{GPa}[55])$ is the direct consequence of the enhanced network connectivity and the accompanied presence of additional network constraints, similarly to silicon oxynitride (SiON) glasses [56]. Before continuing this discussion, we need to note the mismatch in hardness obtained for the C1-SiOC-1100 glass $(H=11.4 \mathrm{GPa})$ investigated in the actual study and the previously published Vickers hardness values for SiOC glasses of 8.2 to $9.3 \mathrm{GPa}[10,13]$. This discrepancy is attributed to the large contribution of elastic deformation to the indentation response of glasses. This manifests in marked differences between the contact area under load, which determines the hardness $H$, and the size of the residual hardness imprint after unloading, which is used for evaluating the Vickers hardness $H_{\mathrm{v}}[57]$.

Unlike SiOC glasses, the improved hardness of the SiOC glass-ceramics is governed by a complex interplay between the mechanical stability, volume fraction and distribution of the residual silica glass matrix and the $\beta$-SiC nanoparticles as well as the segregated carbon [36]. Here, the $\beta$-SiC nanoparticles are supposed to be responsible for the improved hardness of the SiOC glass-ceramics, as polycrystalline $\beta$-SiC exhibits a Vickers hardness $H_{v}$ of 27.1 to $34.1 \mathrm{GPa}$ [58]. Note, that the volume fraction of segregated carbon seems to have only little impact on the hardness. This is evident from the comparison of the $\mathbf{S i C} / \mathbf{S i O}_{2}$ $1600(H=10.6 \mathrm{GPa})$ and C12-SiOC-1600 $(H=10.5 \mathrm{GPa})$ glass-ceramics, which consist of an almost identical volume fraction of $\beta$-SiC nanoparticles, but zero and 12 vol.\% segregated carbon, respectively. The same conclusion can be done upon comparing C1-SiOC-1600 $(H=$ 11.0 GPa) and C16-SiOC-1600 $(H=10.6 \mathrm{GPa})$, revealing comparable amounts of $\beta$-SiC but 1 and 16 vol.\% of segregated carbon, respectively. Interestingly, only marginal differences in hardness are distinguishable between the C1-SiOC-1100 glass ( $H=11.4 \mathrm{GPa})$ and the $\mathbf{C 1}$ SiOC-1600 glass-ceramic $(H=11.0 \mathrm{GPa})$. This result is in clear contrast to a previous study, where an increasing hardness was noticed upon phase separation in a SiOC glass [13]. This was related to an increase in density, which is indeed occurring during phase separation (cf. Table 1), though effects related to the elimination of residual porosity in the SiOC glass were also considered. 
The brittleness of crystalline metals as well as metallic glasses can be correlated to the ratio between shear and bulk modulus (Pugh ratio $\mathrm{G} / \mathrm{K}$ ) [59]. Metallic glasses show a tough-tobrittle transition at $\mathrm{G} / \mathrm{K}>0.41-0.43$ [60]. In this context, Pugh ratios of 0.83 for $\mathbf{C 1 - S i O C -}$ 1600, 0.86 for C12-SiOC-1600 and 0.85 for C16-SiOC-1600, would imply a brittle fracture behavior. The chemical composition has no significant influence on the Pugh ratio of SiOC glass-ceramics. Additionally, the index of brittleness $B=H / K_{\mathrm{lc}}$, which relates the resistance against plastic deformation to the resistance against fracture, was determined for $\mathbf{C 1 - S i O C}$ $1600(B=$ $\left.15 \mu \mathrm{m}^{-0.5}\right)$, C12-SiOC-1600 $\left(B=11 \mu \mathrm{m}^{-0.5}\right)$ and vitreous silica $\left(B=13 \mu \mathrm{m}^{-0.5}\right)$, where higher values correspond to more brittle material [61]. For the calculation the indentation hardness determined in this study was used, whereas values for fracture toughness $\mathrm{K}_{\mathrm{lc}}$ were taken from Ref. [62]. As opposed to the Pugh ratio, the index of brittleness displays a notable dependence on the chemical composition. Sample C1-SiOC-1600 with only 1 vol.\% of segregated carbon appears to be more brittle than vitreous silica. However, the presence of 12 vol.\% segregated carbon in C12-SiOC-1600 has the opposite effect and drastically reduces the brittleness even below the level of vitreous silica. This behavior is in line with the experiences made during grinding of the samples and clearly signifies the importance of both the chemical and phase composition for the mechanical performance of SiOC glasses and glass-ceramics. This argumentation is also supported by previous observations regarding the effects of phase separation on the mechanical stability of alkali-alkaline earth silicate or alkali-borosilicate glasses [55, 63-65]. Tuning the volume fraction and structure of the separated phases is therefore supposed as a promising route towards the fabrication of SiOC materials with an enhanced toughness.

For a potential application of SiOC glasses and glass-ceramics at elevated temperatures, a high creep resistance, i.e., low strain-rate sensitivity, is of paramount importance. Using a nanoindentation strain-rate jump test [27], very low strain-rate sensitivities of 0.0059 to 0.0107 were determined for the SiOC glass and glass-ceramics. The results obtained for both the C1-SiOC-1100 glass $(m=0.0059)$ and the $\mathbf{S i O}_{2} / \mathbf{S i C}-1600(m=0.0060)$ glassceramic are very close to the values reported for vitreous silica $(m=0.0068-0.0150$ [66$68]$ ), which displays no significant creep deformation at room temperature [69, 70]. With respect to this result, we speculate the creep response of SiOC materials with low amounts of segregated carbon to be determined by the creep resistance of the vitreous silica glass matrix. Nevertheless, regarding the $\mathrm{SiOC}$ glass-ceramics a slight but still detectable increase of the strain-rate sensitivity from $0.0060\left(\mathrm{SiO}_{2} / \mathrm{SiC}-1600\right)$ to 0.0107 (C12-SiOC-1600) is seen with increasing amounts of segregated carbon. A higher strain-rate sensitivity in glasses normally signifies a homogenization of the plastic flow [71]. With the presence of a homogeneously dispersed phase of segregated carbon in the vitreous silica glass matrix, fertile sites for a shear-mediated plastic flow are created inside the material.

\section{Conclusions}

Silicon oxycarbides are known to possess increased mechanical properties like Young's modulus and hardness. The present study rationalizes the various impacts on their elastic 
and plastic properties caused by the chemical/phase compositional variability inherent to the SiOC system and gives further insight in the thermal stability of SiOC glass-ceramics.

The elastic properties of silicon oxycarbides are influenced by both phase composition (i.e. volume fraction of $\beta$-SiC or fraction of $\mathrm{Si}-\mathrm{C}$ bonds in $\mathrm{Si}-\mathrm{O}-\mathrm{C}$ glass network and volume fraction of segregated carbon) as well as by their microstructure (i.e. SiOC glass vs. glassceramic; phase separation). Whereas Young's modulus is increasing with increasing volume fraction of $\beta-\mathrm{SiC}$ nanoparticles/Si-C bonds and decreasing with increasing amount of segregated carbon, it is not significantly affected upon phase separation. In contrast, Poisson's ratio, and consequently the atomic packing density, is independent of the chemical composition, but is significantly influenced by the phase separation. Both, the development of Young's modulus and Poisson's ratio, can be considered as direct consequences of: (i) the highly cross-linked network architecture of SiOC glasses due to the presence of mixed-bonds $\mathrm{SiO}_{4-\mathrm{x}} \mathrm{C}_{\mathrm{x}}$ tetrahedra; (ii) the decrease of the cross-linking degree of the glassy network during the phase separation and (iii) the high stiffness of crystalline $\beta$-SiC.

Thermal annealing of SiOC glass-ceramics leads to an increase in Young's modulus. It is demonstrated that this relies in an increased ordering of the dispersed phases segregated carbon and $\beta-S i C$ as evidenced by XRD and Raman spectroscopy and not in a change of the glassy silica matrix as testified by an unbiased Poisson's ratio and temperature sensitivity of Young's modulus. This implies, that the silica-rich glassy matrix of SiOC glass-ceramics is stable at high temperatures and longer holding times.

The plastic properties of SiOC glass-ceramics are significantly influenced by the volume fractions of both segregated carbon and $\beta-S i C$ nanoparticles. The segregated carbon phase reduces brittleness and induces additional sites for sliding during plastic deformation; whereas, the hardness is governed by the volume fraction of $\beta-S i C$ nanoparticles due to their comparably high hardness. Interestingly, the hardness in SiOC seems to be not affected by phase separation.

\section{Acknowledgements}

The authors are grateful for financial support provided from the Deutsche Forschungsgemeinschaft (IO 64/7-1, "High-Temperature Creep in SiOC-Based Glasses and Glass-Ceramics"). 


\section{References}

[1] P. Colombo, G. Mera, R. Riedel, G.D. Soraru, Polymer-derived ceramics: 40 years of research and innovation in advanced ceramics, J. Am. Ceram. Soc. 93(7) (2010) 1805-1837. 10.1111/j.15512916.2010.03876.x.

[2] C. Stabler, E. Ionescu, M. Graczyk-Zajac, I. Gonzalo-Juan, R. Riedel, Silicon oxycarbide glasses and glass-ceramics: "All-Rounder" materials for advanced structural and functional applications, J. Am. Ceram. Soc. 101(11) (2018) 4817-4856. 10.1111/jace.15932.

[3] Y.D. Blum, D.B. MacQueen, H.-J. Kleebe, Synthesis and characterization of carbon-enriched silicon oxycarbides, J. Eur. Ceram. Soc. 25(2-3) (2004) 143-149. 10.1016/j.jeurceramsoc.2004.07.019.

[4] H.-J. Kleebe, Y.D. Blum, SiOC ceramic with high excess free carbon, J. Eur. Ceram. Soc. 28(5) (2008) 1037-1042. 10.1016/j.jeurceramsoc.2007.09.024.

[5] H. Brequel, J. Parmentier, S. Walter, R. Badheka, G. Trimmel, S. Masse, J. Latournerie, P. Dempsey, C. Turquat, A. Desmartin-Chomel, L.L. Neindre-Prum, U.A. Jayasooriya, D. Hourlier, H.J. Kleebe, G.D. Soraru, S. Enzo, F. Babonneau, Systematic Structural Characterization of the High-Temperature Behavior of Nearly Stoichiometric Silicon Oxycarbide Glasses, Chem. Mater. 16(13) (2004) 2585-2598. 10.1021/cm049847a.

[6] S.J. Widgeon, S. Sen, G. Mera, E. lonescu, R. Riedel, A. Navrotsky, 29Si and 13C Solid-State NMR Spectroscopic Study of Nanometer-Scale Structure and Mass Fractal Characteristics of Amorphous Polymer Derived Silicon Oxycarbide Ceramics, Chem. Mater. 22(23) (2010) 6221-6228. $10.1021 / \mathrm{cm} 1021432$.

[7] L. Bois, J. Maquet, F. Babonneau, D. Bahloul, Structural Characterization of Sol-Gel Derived Oxycarbide Glasses. 2. Study of the Thermal Stability of the Silicon Oxycarbide Phase, Chem. Mater. 7(5) (1995) 975-981. 10.1021/cm00053a025.

[8] F. Rosenburg, E. lonescu, N. Nicoloso, R. Riedel, High-Temperature Raman Spectroscopy of NanoCrystalline Carbon in Silicon Oxycarbide, Materials (Basel) 11(1) (2018) 1-9. doi:10.3390/ma11010093.

[9] G.D. Soraru, G. D'Andrea, R. Campostrini, F. Babonneau, G. Mariotto, Structural characterization and high-temperature behavior of silicon oxycarbide glasses prepared from sol-gel precursors containing Si-H bonds, J. Am. Ceram. Soc. 78(2) (1995) 379-387. 10.1111/j.1151-

2916.1995.tb08811.x.

[10] G.D. Soraru, E. Dallapiccola, G. D'Andrea, Mechanical characterization of sol-gel-derived silicon oxycarbide glasses, J. Am. Ceram. Soc. 79(8) (1996) 2074-2080. 10.1111/j.1151-2916.1996.tb08939.x. [11] T. Rouxel, G. Massouras, G.-D. Soraru, High temperature behavior of a gel-derived SiOC glass: elasticity and viscosity, J. Sol-Gel Sci. Technol. 14(1) (1999) 87-94.

[12] T. Rouxel, G.-D. Soraru, J. Vicens, Creep viscosity and stress relaxation of gel-derived silicon oxycarbide glasses, J. Am. Ceram. Soc. 84(5) (2001) 1052-1058. 10.1111/j.1151-2916.2001.tb00789.x. [13] H.-J. Kleebe, C. Turquat, G.D. Soraru, Phase separation in an SiCO glass studied by transmission electron microscopy and electron energy-loss spectroscopy, J. Am. Ceram. Soc. 84(5) (2001) 10731080. 10.1111/j.1151-2916.2001.tb00792.x.

[14] C. Moysan, R. Riedel, R. Harshe, T. Rouxel, F. Augereau, Mechanical characterization of a polysiloxane-derived SiOC glass, J. Eur. Ceram. Soc. 27(1) (2006) 397-403.

10.1016/j.jeurceramsoc.2006.01.016.

[15] G.M. Renlund, S. Prochazka, R.H. Doremus, Silicon oxycarbide glasses. Part II. Structure and properties, J. Mater. Res. 6(12) (1991) 2723-2734. 10.1557/JMR.1991.2723.

[16] B. Papendorf, E. Ionescu, H.-J. Kleebe, C. Linck, O. Guillon, K. Nonnenmacher, R. Riedel, Hightemperature creep behavior of dense SiOC-based ceramic nanocomposites: microstructural and phase composition effects, J. Am. Ceram. Soc. 96(1) (2013) 272-280. 10.1111/jace.12067.

[17] E. Ionescu, C. Balan, H.-J. Kleebe, M.M. Mueller, O. Guillon, D. Schliephake, M. Heilmaier, R. Riedel, High-temperature creep behavior of SiOC glass-ceramics: influence of network carbon versus segregated carbon, J. Am. Ceram. Soc. 97(12) (2014) 3935-3942. 10.1111/jace.13206. 
[18] C. Stabler, F. Roth, M. Narisawa, D. Schliephake, M. Heilmaier, S. Lauterbach, H.-J. Kleebe, R. Riedel, E. Ionescu, High-temperature creep behavior of a SiOC glass ceramic free of segregated carbon, J. Eur. Ceram. Soc. 36(15) (2016) 3747-3753. 10.1016/j.jeurceramsoc.2016.04.015.

[19] C. Stabler, D. Schliephake, M. Heilmaier, T. Rouxel, H.-J. Kleebe, M. Narisawa, R. Riedel, E. Ionescu, Influence of SiC/Silica and Carbon/Silica Interfaces on the High-Temperature Creep of Silicon Oxycarbide-Based Glass Ceramics: A Case Study, Advanced Engineering Materials 1800596 (2018) 111. 10.1002/adem.201800596.

[20] A. Makishima, J.D. Mackenzie, Direct calculation of Young's modulus of glass, J. Non-Cryst. Solids 12(1) (1973) 35-45. 10.1016/0022-3093(73)90053-7.

[21] C. Stabler, P. Stein, R. Riedel, E. Ionescu, A. Reitz, B. Albert, Thermal Properties of SiOC Glasses and Glass Ceramics at Elevated Temperatures, Materials (Basel) 11(279) (2018) 1-18.

[22] M. Narisawa, S. Watase, K. Matsukawa, T. Dohmaru, K. Okamura, White Si-O-C(-H) particles with photoluminescence synthesized by decarbonization reaction on polymer precursor in a hydrogen atmosphere, Bull. Chem. Soc. Jpn. 85(6) (2012) 724-726. 10.1246/bcsj.20110357.

[23] E. Radovanovic, M.F. Gozzi, M.C. Goncalves, I.V.P. Yoshida, Silicon oxycarbide glasses from silicone networks, J. Non-Cryst. Solids 248(1) (1999) 37-48. 10.1016/S0022-3093(99)00101-5. [24] W.C. Oliver, G.M. Pharr, An improved technique for determining hardness and elastic modulus using load and displacement sensing indentation experiments, Journal of Materials Research 7(6) (1992) 1564-1583. 10.1557/Jmr.1992.1564.

[25] X.D. Li, B. Bhushan, A review of nanoindentation continuous stiffness measurement technique and its applications, Mater. Charact. 48(1) (2002) 11-36.

[26] G.M. Pharr, J.H. Strader, W.C. Oliver, Critical issues in making small-depth mechanical property measurements by nanoindentation with continuous stiffness measurement, Journal of Materials Research 24(3) (2009) 653-666. Doi 10.1557/Jmr.2009.0096.

[27] R. Limbach, B.P. Rodrigues, L. Wondraczek, Strain-rate sensitivity of glasses, Journal of NonCrystalline Solids 404 (2014) 124-134.

[28] L. Shen, W.C.D. Cheong, Y.L. Foo, Z. Chen, Nanoindentation creep of tin and aluminium: A comparative study between constant load and constant strain rate methods, Materials Science and Engineering A: Structural Materials Properties Microstructure and Processing, 2012, pp. 505-510. [29] B.N. Lucas, W.C. Oliver, Indentation Power-Law Creep of High-Purity Indium, Metall. Mater. Trans. A 30(3) (1999) 601-610. 10.1007/S11661-999-0051-7.

[30] J. Hay, Introduction to Instrumented Indentation Testing, Exp. Techniques 33(6) (2009) 66-72. Doi 10.1111/J.1747-1567.2009.00541.X.

[31] R. Limbach, A. Winterstein-Beckmann, J. Dellith, D. Möncke, L. Wondraczek, Plasticity, crack initiation and defect resistance in alkali-borosilicate glasses: From normal to anomalous behavior, Journal of Non-Crystalline Solids 417-418 (2015) 15-27.

[32] J.M. Bind, Phase transformation during hot-pressing of cubic silicon carbide, Mater. Res. Bull. 13(2) (1978) 91-6. 10.1016/0025-5408(78)90071-5.

[33] S. Walter, G.D. Soraru, H. Brequel, S. Enzo, Microstructural and mechanical characterization of sol gel-derived Si-O-C glasses, J. Eur. Ceram. Soc. 22(13) (2002) 2389-2400. 10.1016/S09552219(01)00537-4.

[34] T. Rouxel, Elastic properties and short-to medium-range order in glasses, J. Am. Ceram. Soc. 90(10) (2007) 3019-3039. 10.1111/j.1551-2916.2007.01945.x.

[35] A.J. Stryjak, P.W. McMillan, Microstructure and properties of transparent glass-ceramics. Part 2. The physical properties of spinel transparent glass-ceramics, J. Mater. Sci. 13(8) (1978) 1794-1804. 10.1007/BF00548743.

[36] N. Miyata, H. Jinno, Discussion of the indentation hardness of a glass-ceramic with participate microstructure, Journal of Materials Science 17(9) (1982) 2693-2699. 10.1007/BF00543906.

[37] G.D. Soraru, V.M. Sglavo, S. Dirè, G. D'Andrea, F. Babonneau, High-Strength, High-Modulus Silicon-Oxycarbide glasses, in: P. Durán, J.F. Fernández (Eds.) Third EURO-CERAMICS, Faenza Editrice Ibérica S.L., 1993, pp. 1157-1162. 
[38] S. Martinez-Crespiera, E. lonescu, H.-J. Kleebe, R. Riedel, Pressureless synthesis of fully dense and crack-free SiOC bulk ceramics via photo-crosslinking and pyrolysis of a polysiloxane, J. Eur.

Ceram. Soc. 31(5) (2011) 913-919. 10.1016/j.jeurceramsoc.2010.11.019.

[39] G.D. Sorarù, L. Kundanati, B. Santhosh, N. Pugno, Influence of free carbon on the Young's modulus and hardness of polymer-derived silicon oxycarbide glasses, J. Am. Ceram. Soc. 0(0) (2018) 1-7. 10.1111/jace.16131.

[40] S. Spinner, G.W. Cleek, Temperature dependence of Young's modulus of vitreous germania and silica, J. Appl. Phys. 31 (1960) 1407-1410. 10.1063/1.1735852.

[41] D.J. Lacks, First-Order Amorphous-Amorphous Transformation in Silica, Phys. Rev. Lett. 84(20) (2000) 4629-4632. 10.1103/PhysRevLett.84.4629.

[42] O. Benzine, S. Bruns, Z. Pan, K. Durst, L. Wondraczek, Local deformation of glasses is mediated by rigidity fluctuation and granularity, Adv. Sci. 5 (2018) 1800916/1-1800916/9. DOI:

10.1002/advs.201800916.

[43] S. Sawamura, L. Wondraczek, Scratch hardness of glass, Phys. Rev. Mater. (in press (2018)).

[44] M. Idriss, F. Celarie, Y. Yokoyama, F. Tessier, T. Rouxel, Evolution of the elastic modulus of Zr-CuAl BMGs during annealing treatment and crystallization: Role of $\mathrm{Zr} / \mathrm{Cu}$ ratio, J. Non-Cryst. Solids 421 (2015) 35-40. 10.1016/j.jnoncrysol.2015.04.028.

[45] C.A. Angell, Perspective on the glass transition, Journal of Physics and Chemistry of Solids 49(8) (1988) 863-871. https://doi.org/10.1016/0022-3697(88)90002-9.

[46] M.A. Mazo, A. Tamayo, J. Rubio, Advanced silicon oxycarbide-carbon composites for high temperature resistant friction systems, J. Eur. Ceram. Soc. 36(10) (2016) 2443-2452.

10.1016/j.jeurceramsoc.2016.03.012.

[47] D. Balzar, N. Audebrand, M.R. Daymond, A. Fitch, A. Hewat, J.I. Langford, A. Le Bail, D. Louer, O. Masson, C.N. McCowan, N.C. Popa, P.W. Stephens, B.H. Toby, Size-strain line-broadening analysis of the ceria round-robin sample, J. Appl. Crystallogr. 37(6) (2004) 911-924.

$10.1107 /$ S0021889804022551.

[48] H. Brequel, J. Parmentier, G.D. Sorar, L. Schiffini, S. Enzo, Study of the phase separation in amorphous silicon oxycarbide glasses under heat treatment, Nanostruct. Mater. 11(6) (1999) 721 731. 10.1016/S0965-9773(99)00360-8.

[49] R. Brueckner, Mechanical properties of glasses, VCH, 1991, pp. 665-713.

[50] A. Pedone, G. Malavasi, A.N. Cormack, U. Segre, M.C. Menziani, Insight into Elastic Properties of Binary Alkali Silicate Glasses; Prediction and Interpretation through Atomistic Simulation Techniques, Chem. Mater. 19(13) (2007) 3144-3154. 10.1021/cm062619r.

[51] Q. Zhao, M. Guerette, L. Huang, Nanoindentation and Brillouin light scattering studies of elastic moduli of sodium silicate glasses, J. Non-Cryst. Solids 358(3) (2012) 652-657.

10.1016/j.jnoncrysol.2011.10.034.

[52] P. Sellappan, T. Rouxel, F. Celarie, E. Becker, P. Houizot, R. Conradt, Composition dependence of indentation deformation and indentation cracking in glass, Acta Mater. 61(16) (2013) 5949-5965.

10.1016/j.actamat.2013.06.034.

[53] S. Sawamura, R. Limbach, H. Behrens, L. Wondraczek, Lateral deformation and defect resistance of compacted silica glass: Quantification of the scratching hardness of brittle glasses, J. Non-Cryst. Solids 481 (2018) 503-511. 10.1016/j.jnoncrysol.2017.11.035.

[54] G.N. Greaves, A.L. Greer, R.S. Lakes, T. Rouxel, Poisson's ratio and modern materials, Nat. Mater. 10(11) (2011) 823-837. 10.1038/nmat3134.

[55] R. Limbach, A. Winterstein-Beckmann, J. Dellith, D. Moencke, L. Wondraczek, Plasticity, crack initiation and defect resistance in alkali-borosilicate glasses: From normal to anomalous behavior, J. Non-Cryst. Solids 417-418 (2015) 15-27. 10.1016/j.jnoncrysol.2015.02.019.

[56] G.L. Paraschiv, S. Gomez, J.C. Mauro, L. Wondraczek, Y. Yue, M.M. Smedskjaer, Hardness of Oxynitride Glasses: Topological Origin, J. Phys. Chem. B 119(10) (2015) 4109-4115.

10.1021/jp512235t. 
[57] W.C. Oliver, G.M. Pharr, Measurement of hardness and elastic modulus by instrumented indentation: advances in understanding and refinements to methodology, J. Mater. Res. 19(1) (2004) 3-20. 10.1557/jmr.2004.19.1.3.

[58] Y.C. Cha, G. Kim, H.J. Doerr, R.F. Bunshah, Effects of activated reactive evaporation process parameters on the microhardness of polycrystalline silicon carbide thin films, Thin Solid Films 253(1) (1994) 212-217. https://doi.org/10.1016/0040-6090(94)90322-0.

[59] S.F. Pugh, XCII. Relations between the elastic moduli and the plastic properties of polycrystalline pure metals, The London, Edinburgh, and Dublin Philosophical Magazine and Journal of Science 45(367) (1954) 823-843. 10.1080/14786440808520496.

[60] J.J. Lewandowski, W.H. Wang, A.L. Greer, Intrinsic plasticity or brittleness of metallic glasses, Philosophical Magazine Letters 85(2) (2005) 77-87. 10.1080/09500830500080474.

[61] B.R. Lawn, D.B. Marshall, Hardness, toughness, and brittleness: an indentation analysis, J. Am. Ceram. Soc. 62(7-8) (1979) 347-350. 10.1111/j.1151-2916.1979.tb19075.x.

[62] T. To, C. Stabler, E. lonescu, R. Riedel, F. Célarié, T. Rouxel, Fracture toughness and crack behavior of dense SiOC glass ceramics, Journal of the European Ceramic Society (submitted). [63] A.K. Seal, P. Chakraborti, N.R. Roy, S. Mukherjee, M.K. Mitra, G.C. Das, Effect of phase separation on the fracture toughness of SiO2-B2O3-Na2O glass, Bull. Mater. Sci. 28(5) (2005) 457-460.

10.1007/BF02711236.

[64] S. Deriano, T. Rouxel, M. LeFloch, B. Beuneu, Structure and mechanical properties of alkalialkaline earth-silicate glasses, Phys. Chem. Glasses 45(1) (2004) 37-44.

[65] S. Cheng, C. Song, P. Ercius, Indentation cracking behaviour and structures of nanophase separation of glasses, Physics and Chemistry of Glasses - European Journal of Glass Science andTechnology Part B 58(6) (2017) 237-242. 10.13036/17533562.58.6.040.

[66] R. Limbach, B.P. Rodrigues, L. Wondraczek, Strain-rate sensitivity of glasses, J. Non-Cryst. Solids 404 (2014) 124-134. 10.1016/j.jnoncrysol.2014.08.023.

[67] D. Peykov, E. Martin, R.R. Chromik, R. Gauvin, M. Trudeau, Evaluation of strain rate sensitivity by constant load nanoindentation, J. Mater. Sci. 47(20) (2012) 7189-7200. 10.1007/s10853-012-6665-y.

[68] A.A. Elmustafa, D.S. Stone, Strain rate sensitivity in nanoindentation creep of hard materials, J. Mater. Res. 22(10) (2007) 2912-2916. 10.1557/JMR.2007.0374.

[69] T. Chudoba, F. Richter, Investigation of creep behaviour under load during indentation experiments and its influence on hardness and modulus results, Surf. Coat. Technol. 148(2-3) (2001) 191-198. 10.1016/S0257-8972(01)01340-8.

[70] A.C. Fischer-Cripps, A simple phenomenological approach to nanoindentation creep, Mater. Sci. Eng., A A385(1-2) (2004) 74-82. 10.1016/j.msea.2004.04.070.

[71] H. Meinhard, P. Grau, G. Berg, S. Mosch, Hardness and flow behavior of glass in the nanometer range. An interpretation of the load dependence of the hardness, Glass Sci. Technol.

(Frankfurt/Main) 70(11) (1997) 333-339. 


\section{Table Captions}

Table 1. Chemical compositions of the monolithic SiOC samples, their estimated phase compositions and the corresponding skeletal densities $\rho$. Volume fractions of $\mathrm{SiO}_{2}$, $\mathrm{SiC}$ and segregated carbon $\mathrm{C}_{\text {segr }}$ are calculated by means of the following densities: $\rho\left(\mathrm{SiO}_{2}\right)=2.20 \mathrm{~g} / \mathrm{cm}^{3}[15], \rho(\beta-\mathrm{SiC})=3.22 \mathrm{~g} / \mathrm{cm}^{3}[32], \rho\left(\mathrm{C}_{\text {segr }}\right)=$ $1.82 \mathrm{~g} / \mathrm{cm}^{3}$ (Graphitized Mesoporous Carbons GMC, Sigma-Aldrich, CAS-\# 133386-4).

Table 2. Room temperature elastic properties and plasticity of SiOC glasses and glassceramics: Young's modulus $E$, shear modulus $G$, bulk modulus $K$, Poisson's ratio $v$, hardness $H$ and strain-rate sensitivity $m$. Literature data for a SiOC glass and Suprasil vitreous silica are added for comparison.

Table 3. Skeletal density $\rho$ and elemental composition of the investigated as-prepared SiOC glass-ceramics and after a thermal treatment.

Table 4. Effects of a thermal treatment on the degree of graphitization of the segregated carbon in SiOC glass-ceramics as determined from Raman spectroscopy: Average crystallite size $L_{a}$, average distance between two defects $L_{D}$. $A_{D} / A_{G}$ describes the ratio between the areas assigned to the $D$ and $G$ band, respectively.

\section{Figure Captions}

Figure 1. Ternary phase diagram in the system Si-O-C. The dashed line (parallel to the $\mathrm{SiO}_{2}-\mathrm{C}$ tie-line) marks that the segregated carbon content increases from $\mathrm{SiC} / \mathrm{SiO}_{2}-1600$ to $\mathrm{C} 16-\mathrm{SiOC}-1600$ without large variations in the $\mathrm{SiC}$ content.

Figure 2. Room temperature Young's modulus of SiOC glasses (open symbols) and glassceramics (filled symbols) as a function of (a) volume fraction of $\mathrm{sp}^{2}$-hybridized segregated carbon and (b) the volume fraction of $\mathrm{Si}-\mathrm{C}$ bonds (as for SiOC glasses) or B-SiC (as for SiOC glass-ceramics). Literature values (black symbols) are added for comparison. Dashed lines were drawn as a guide for the eyes.

Figure 3. Temperature dependence of the Young's modulus of the SiOC glass-ceramics investigated in this study. The experimental error is estimated to be $\pm 1 \mathrm{GPa}$ (i.e., $<2 \%$ ).

Figure 4. Temperature dependence of the Young's modulus of the as-prepared (a) C1SiOC-1600, (b) C12-SiOC-1600 and (c) C16-SiOC-1600 SiOC glass-ceramics, respectively, and after a thermal treatment at different temperatures and for varying durations. Lines drawn are fits to the experimental data. (d) Temperature dependence of the Young's modulus normalized to its value at room temperature (displayed by trendlines). The experimental error is estimated to be $\pm 1 \mathrm{GPa}$ (i.e., $<2 \%$ ).

Figure 5. X-ray diffraction patterns $\left(\mathrm{Mo} \mathrm{K}_{\mathrm{a}}\right)$ of $\mathrm{SiOC}$ glass-ceramics prior and after annealing at high temperatures: (a) C1-SiOC-1600; (b) C12-SiOC-1600; (c) C16SiOC-1600. Indexed reflections relate to $\beta-S i C$.

Figure 6. Temperature dependence of the shear modulus $\mathrm{G}$ and Poisson's ratio $v$ of the (a) as-prepared C1-SiOC-1600 SiOC glass-ceramic and (b) after a thermal treatment for 6 days at $1100^{\circ} \mathrm{C}$. 